\section{Studi Kemampuan Spray Tower untuk Penyisihan Polutan Gas Sulfur Dioksida dari Pembakaran Bahan Bakar Industri}

\section{Martheana Kencanawati}

Program Studi Teknik Sipil bidang Rekayasa Sumber Daya Air, Universitas Balikpapan

$\triangle$ martheana@uniba-bpn.ac.id
Sebagian sumber pencemaran sulfur dioksida adalah dari aktivitas manusia seperti gas buangan pabrik maupun kendaraan bermotor. Oleh karena itu, pencegahannya dapat dilakukan oleh manusia sendiri dengan berbagai usaha. Paper ini membahas mengenai upaya pencegahan polusi dari sulfur dioksida dengan menggunakan wet scrubber. Wet scrubber didesain dengan menggunakan mist eliminator tanpa media dan menggunakan air. Variabel dalam penelitian ini adalah debit air, ketinggian sprayer dan susun vertikal sprayer. Gas $\mathrm{SO}_{2}$ dianalisis dengan menggunakan metode konduktivitimetri manual. Pengukuran dengan metode ini dapat diaplikasikan pada $\mathrm{SO}_{2}$ yang memiliki range $\geq 0.05 \mathrm{ppm}$. Hasil yang diperoleh dari penelitian adalah persentase penyisihan $\mathrm{SO}_{2}$ untuk satu tingkat sprayer dengan debit terbesar o,14 Liter/s adalah $74.15 \%$. Satu tingkat sprayer menggunakan ketinggian kolom pada sprayer berjarak $110 \mathrm{~cm}$. Sedangkan untuk dua tingkat prayer dengan ketinggian kolom $110 \mathrm{~cm}$ dan $41 \mathrm{~cm}$ menghasilkan penyisihan $\mathrm{SO}_{2}$ sebesar $97.74 \%$

Kata kunci: sulfur dioksida, spray tower, absorbsi, conductivitymetri

Diajukan: 3 Juli 2019

Direvisi:10 Juli 2019

Diterima: 16 Juli 2019

Dipublikasikan online: 20 Juli 2019

\section{Pendahuluan}

Sulfur dioksida adalah polutan yang dihasilkan dari fasilitas pembangkit panas dan tenaga listrik yang mempergunakan minyak atau batubara yang mengandung sulfur dan emisi pembuangan dari pabrik belerang. Sulfur dioksida juga dapat dihasilkan dari berbagai macam sumber emisi seperti transportasi, pembakaran bahan bakar, proses industri, aktivitas transportasi, pembuangan sampah yang berasal dari proses dekomposisi (de Navers, 2000). Sulfur dioksida di udara tidak hanya berbahaya bagi manusia akan tetapi juga dapat diserap oleh tanaman melalui stomata (WHO, 2000).

Emisi SO2 dari pembakaran bahan bakar bergantung pada kandungan sulfur bahan bakar dan komposisi bahan bakar tersebut (seperti kandungan sulfur, nilai kalor dan konsentrasi alkali). Konversi sulfur pada bahan bakar proporsional dengan konsentrasi alkali pada senyawa bahan bakar. Kandungan sulfur dioksida memiliki efek terbesar pada konversi sulfur karena adanya kandungan Natrium pada penyisihan SOx dengan absorber (Hamlin, 1993).

Salah satu cara untuk mereduksi emisi gas $\mathrm{SO} 2$ adalah dengan memanfaatkan pengolahan dengan proses absorbsi. Sistem ini telah terbukti bekerja secara kontinyu dan secara nyata menjaga level emisi yang diperbolehkan yaitu di bawah New Source Performance Standard (NSPS) sebesar $1.0 \mathrm{lb} / 1000 \mathrm{lbs}$ bahan yang terbakar untuk partikulat dan level EPA sebesar 25 ppm untuk $\mathrm{SO}_{2}$ (Weaver dkk, 2003).

Penelitian ini diharapkan untuk mencapai pembuktian tentang bagaimana efektivitas spray tower dalam penyerapan gas $\boldsymbol{S O}_{\mathbf{2}}$ dengan menggunakan air sebagai media penyerap. Air yang digunakan adalah air ledeng PDAM kualitas $C$ yang ditinjau dari sudut kualitas akan cukup menyulitkan dalam penggunaannya di industri-industri seperti industri gula, cane, tembakau yang membutuhkan kuantitas air dalam jumlah yang besar dan mempertimbangkan faktor kualitas air. Kualitas air yang dimaksud yaitu warna, kekeruhan, bau, dan bahan organik yang tinggi. Di sisi lain kandungan organik yang tinggi ini akan mempermudah proses pengikatan ion-ion antara alkali tanah (natrium atau sodium) dengan suatu senyawa bersifat asam.

\section{Metode}

Penelitian ini dititik beratkan pada kemampuan air untuk menyerap gas $\mathrm{SO}_{2}$ dengan menggunakan sistem spray tower. Penelitian dilakukan untuk mengetahui efisiensi penyisihan gas $\boldsymbol{S O}_{2}$ menggunakan alat spray tower dengan memvariasikan debit air, tingkatan spray nozzle yang digunakan dan pengaruh ketinggian penempatan nozzle yang akan dilewatkan pada spray tower. Korelasi antara persen penyisihan $\mathrm{SO}_{2}$ dengan debit air dan juga dengan ketinggian sprayer.

Cara mensitasi artikel ini:

Kencanawati, M (2019) Studi Kemampuan Spray Tower untuk Penyisihan Polutan Gas Sulfur Dioksida dari Pembakaran Bahan Bakar Industri. Buletin Profesi Insinyur 2(1) 016-019 
Gas $\mathrm{SO}_{2}$ dalam skala laboratorium didesiain dengan model pembakaran. Parameter operasional penyisihan gas $\mathrm{SO}_{2}$ menggunakan alat spray tower adalah tekanan, temperatur air dan udara, viskositas udara, komposisi kimia gas buang, laju alir, target efisiensi penyisihan, dan perubahan $\mathrm{pH}$ pada liquor outlet. Konsentrasi gas $\mathrm{SO}_{2}$ sebelum dan sesudah melewati spray tower diukur dengan menggunakan impinger. Sistem berlangsung secara kontinyu dengan pengaturan pembakaran yang konstan dan aliran udara yang masuk ke dalam spray tower juga konstan. Pelaksanaan penelitian diawali dengan penelitian pendahuluan untuk mengetahui debit udara yang masuk dengan menggunakan prinsip pitot tube yaitu untuk mengetahui perbedaan tekanan udara yang mengalir dalam pipa. Skema penelitian dapat dilihat pada Gambar 1.

\section{Metode Sampling}

Sampling gas dilakukan dengan menggunakan impinger. Inlet gas kotor dan outlet dari spray tower dihubungkan pada impinger. Prosedur analisa $\mathrm{SO}_{2}$ dilakukan dengan metode manual conductivitimetri (Booras dan Zimmer, 1968). Metode ini digunakan karena yang paling sering di gunakan dan pada umumnya dapat menghasilkan hasil analisa yang lebih akurat dengan presisi $0.05 \mathrm{ppm}$ range $\mathrm{SO}_{2}$. Sampling dilakukan selama satu minggu dan dilakukan dengan periode pengambilan sampel 10 kali sampling dalam 1 hari.

\section{Hasil Kerja}

Kemampuan spray tower untuk menyisihkan gas $\mathrm{SO}_{2}$ sangat dipengaruhi debit air, ketinggian sprayer dan juga tingkatan sprayer. Hal ini juga berhubungan dengan rasio liquid/gas (L/G) yang nantinya dikorelasikan dengan persentase penyisihan efisiensi $\mathrm{SO}_{2}$. Kemampuan spray tower ini dapat ditinjau dari waktu kontak, luas permukaan kontak, suhu, $\mathrm{pH}$ dari air absorban sehingga kapasitas penyerapan $\mathrm{SO}_{2}$ dapat di nyatakan dalam suatu persamaan antara kinerja dengan faktor yang mendukung.

Pengukuran dengan manual conductivitymetri method dipilih karena dapat diaplikasikan pada sulfur dioksida yang memiliki range $\geq 0.05 \mathrm{ppm}$. Daya hantar listrik pada suatu larutan bergantung pada keadaan dan konsentrasi ion yang hadir pada larutan. Ketika suatu tegangan listrik (voltage) melalui elektroda di celupkan ke dalam larutan, ion yang terlarut melalui elektroda yaitu kation (ion positif) akan bermigrasi ke ion negatif (anoda), dan demikian sebaliknya. Perpindahan antar ion ini dalam larutan akan menimbulkan arus listrik. Arus listrik akan lebih besar pada larutan pekat karena banyak ion pembawa terdapat larutan tersebut. Arus listrik akan bergerak sesuai muatan kapasitas ion. Ion hidrogen dapat bergerak lebih cepat dibandingkan ion lain pada larutan aqua.

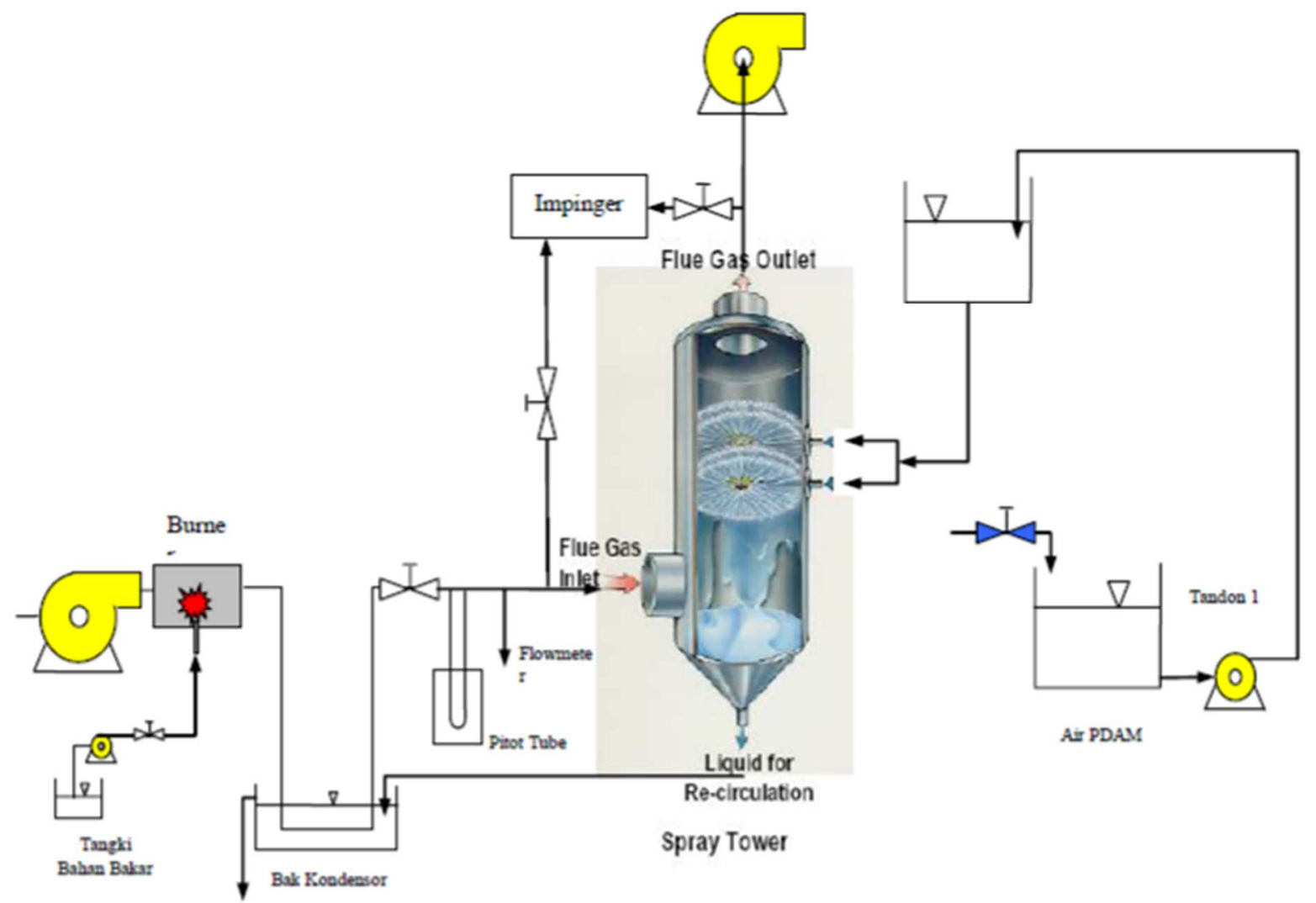

Gambar 1 Skema penelitian 


\section{Pengaruh Debit Air Dan Ketinggian Sprayer Pada \% Penyisihan}

Ketinggian sprayer berpengaruh pada kontak intim antara gas kotor dengan air yang dilewatkan pada nozzle di dalam spray tower. Sehingga letak sprayer yang semakin tinggi akan mengakibatkan waktu kontak antara gas dengan air semakin lama sehingga konsentrasi $\mathrm{SO}_{2}$ yang terserap dan persentase penyisihan $\mathrm{SO}_{2}$ juga semakin meningkat. Karena spray tower berlangsung secara countercurrent maka fasa gas yang mengalir naik dan akan bertumbukan dengan liquid yang berasal dari butiran air yang dihasilkan nozzle. Nozzle didesain agar cairan dari tetesan kecil dalam jumlah cukup besar dengan laju aliran cairan tertentu akan memberikan luas kontak antar fasa yang lebih besar (area inilah tempat berlangsungnya proses transfer massa). Resistansi terhadap transfer di dalam fasa gas akan mengalami pengurangan karena adanya butiran air yang jatuh.

Pengaruh Debit Air dengan Ketinggian Sprayer untuk 2 Tingkat Sprayer dan Hubungannya dengan Efisiensi

Untuk 2 tingkat sprayer, besar debit air berkorelasi dengan tingkatan sprayer dan ketinggian sprayer juga berpengaruh pada persentase penyisihan $\mathrm{SO}_{2}$ yang tinggi. Hal ini di pengaruhi waktu kontak dan luas bidang kontak dalam spray tower.Terlihat bahwa dengan ketinggian sprayer $110 \mathrm{~cm}$ dan $41 \mathrm{~cm}$ di peroleh persentase penyisihan $97.74 \%$ dengan debit yang paling cepat yaitu 0.14 liter/detik. Hal ini di sebabkan karena setelah berkontak dengan sprayer pertama $0.41 \mathrm{~m}$ kontaminan gas masih mengalami proses tumbukan atau berkontak dengan droplet.Persentase penyisihan $\mathrm{SO}_{2}$ di pengaruhi besarnya debit. Debit air yang paling cepat $(0.14$ liter/detik) maka persentase penyisihan $\mathrm{SO} 2$ yang di peroleh adalah $97.74 \%$. Ketinggian sprayer pada 110 $\mathrm{cm}$ dan $41 \mathrm{~cm}$ menunjukkan persentase penyisihan mencapai $97.74 \%$ ini menunjukkan bahwa ada korelasi yang erat antara debit air dan ketinggian sprayer terhadap efisiensi spray tower. Detail tentang data conductivity dapat dilihat pada Tabel 1 . Sedangkan hubungan antara debit absorben 0,14 liter/dtk, 0,625 liter/detik dan 0,036 liter/detik untuk double sprayer dengan ketinggian berbeda terlihat pada Gambar 2.

Tabel 1 Data conductivity sampel dan kuantitas $\mathrm{SO}_{2}$ dan persen penyisihan data awal untuk satu tingkat sprayer

\begin{tabular}{cccccc}
\hline Variabel & $\begin{array}{c}\text { DHL } \\
\text { sampel } \\
\text { inlet }\end{array}$ & $\begin{array}{c}\text { DHL } \\
\text { sampel } \\
\text { inlet }\end{array}$ & $\begin{array}{c}\text { SO } \\
\text { inlet }\end{array}$ & $\begin{array}{c}\text { SO } \\
\text { outlet }\end{array}$ & $\begin{array}{c}\text { \% } \\
\text { Penyisihan }\end{array}$ \\
\hline Q1H1 & 64.2 & 54.4 & 35.73 & 29.75 & 74.15 \\
Q1H2 & 63.4 & 55.2 & 35.25 & 30.24 & 61.77 \\
Q1H3 & 63.8 & 56.1 & 35.49 & 30.79 & 58.01 \\
Q1H4 & 66.3 & 64.2 & 37.01 & 35.73 & 3.46 \\
& & & & & \\
Q2H1 & 19.8 & 9.3 & 8.64 & 2.23 & 16.73 \\
Q2H2 & 19.4 & 10.9 & 8.40 & 3.21 & 14.20 \\
Q2H3 & 16.5 & 10.2 & 6.63 & 2.78 & 13.24 \\
Q2H4 & 66.5 & 64.2 & 37.14 & 35.73 & 3.78 \\
& & & & & \\
Q3H1 & 19.8 & 17.2 & 8.64 & 7.05 & 18.36 \\
Q3H2 & 19.4 & 18.1 & 8.40 & 7.73 & 7.99 \\
Q3H3 & 60.2 & 56.1 & 33.29 & 30.79 & 7.51 \\
Q3H4 & 13.5 & 13.1 & 4.80 & 4.55 & 5.09 \\
\hline
\end{tabular}

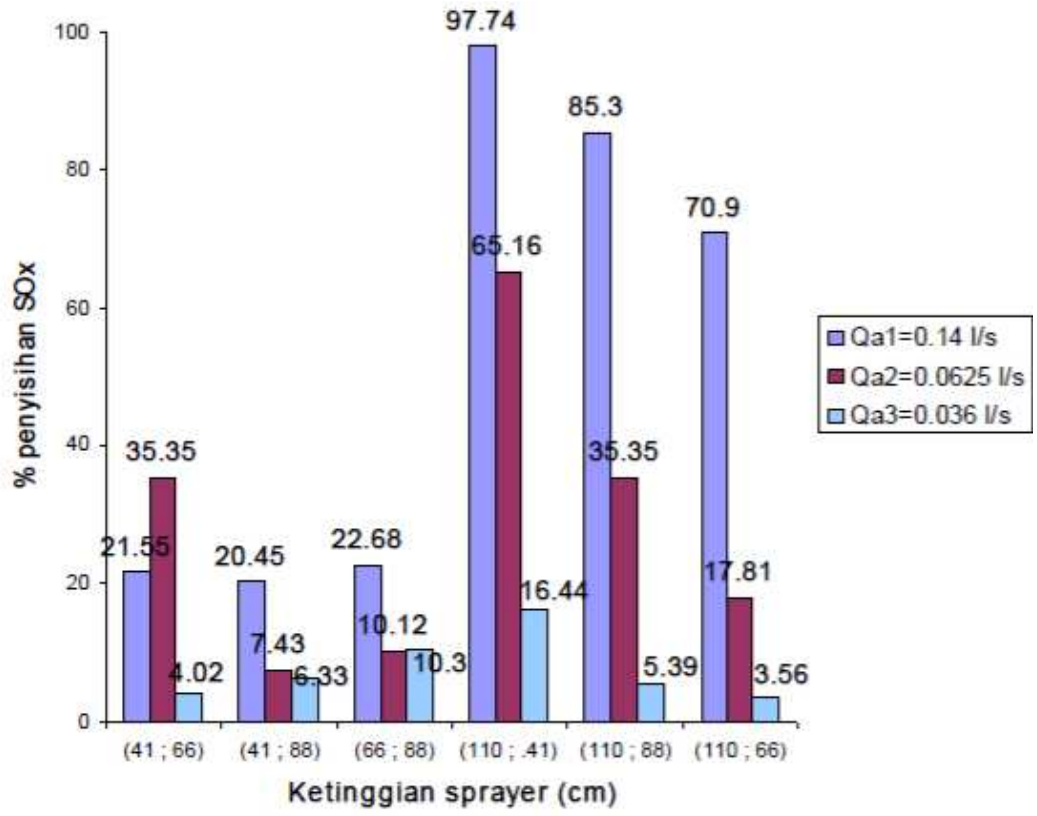

Gambar 2 Hubungan antara debit absorben 0,14 liter/detik, 0,625 liter/detik dan 0,036 liter/detik untuk double sprayer dengan ketinggian berbeda 


\section{Kesimpulan}

Kesimpulan yang dapat ditarik dari penelitian ini adalah:

1. Debit absorber terbesar yaitu 0,014 liter/detik akan menghasilkan kemampuan penyerapan $\mathrm{SO}_{2}$ yang paling besar.

2. Ketinggian dan tingkatan sprayer berpengaruh pada efisiensi, dua tingkat sprayer menghasilkan efisiensi yang lebih besar daripada satu tingkatan sprayer. Semakin tinggi jatuhan berarti waktu kontak dan efisiensi meningkat.

3. Single sprayer menghasilkan penyisihan $\mathrm{SO}_{2}$ sebesar $74.15 \%$ untuk debit 0,14 liter/detik dengan ketinggian sprayer $110 \mathrm{~cm}$.

4. Double sprayer menghasilkan penyisihan $\mathrm{SO}_{2}$ sebesar $97.74 \%$ untuk debit 0,14 liter/detik dengan ketinggian sprayer $110 \mathrm{~cm} ; 41 \mathrm{~cm}$.

\section{Ucapan Terimakasih}

Penulis mengucapkan terimakasih kepada Dr. Ir. Agus Slamet, M.Sc dan Dr. Ir. Rachmat Boedisantoso, M.T.,
Juli Santoso, S.T., Ketua Jurusan Teknik Lingkungan ITS, dan Kepala Laboratorium Jurusan Teknik Lingkungan ITS atas dukungannya dalam melakukan penelitian ini.

\section{Referensi}

Booras, S.G., Zimmer, C. E (1968) A Comparison of ConductivityAnd West-Gaeke Analyses For Sulfur Dioxide, Journal of the Air Pollution Control Association, 18:9, 612-615

DOI: $10.1080 / 00022470.1968 .10469177$

de Navers, N (2000) Air Polution Control Engineering, International Edition, Mc Graw Hill, Singapura

Hamlin, M (1993)., Emission Factor Documentation for AP-42 Section 1.7, LigniteCombustion, Research Triangle Park, New York

Weaver E.H, Barrasso M.J dan Jarvis J.B (2003), An Update of Wet Scrubbing Control Technology for FCCUS-Multiple Pollutant Control, Annual Meeting, (San Antonio), Maret 23-25, AM-03-120, pp 1-14

WHO (2000) Air Quality Guidelines - Second Edition, WHO Regional Publications, European Series, No. 91, WHO Regional Office for Europe, Copenhagen, Denmark 